\title{
Static Analysis of a Tire Sidewall Developed From TAILORED ORganomodifiEd Kaolin/Natural Rubber Vulcanizates
}

\author{
Chinedum Ogonna MGBEMENA*, ThankGod Enatimi BOYE, Ikuobase \\ EMOVON
}

\begin{abstract}
Department of Mechanical Engineering, Federal University of Petroleum Resources, P.M.B 1221, Effurun, Delta State, Nigeria

*mgbemena.ogonna@fupre.edu.ng

(Received: 30-August-2017; accepted: 17-October-2017; published: 30-November-2017)
\end{abstract}

DOI: http://dx.doi.org/10.25073/jaec.201712.83

\begin{abstract}
This paper is on the prediction of stress limits and strain distributions of an automobile tire sidewall developed from Natural Rubber (NR)/Tea Seed Oil (TSO) modified kaolin composites. The stress-strain data report of NR/TSO modified kaolin at filler loading of $10 p h r$ was used to establish parameters characterizing the elastic behaviour of the rubber vulcanizates. The tire model investigated was developed from MATLAB PDE Toolbox. The study was developed on maximum inflation pressure of 0.220632 $M P a$. The $2 D$ Finite Element (FE) model computations for static loading of the tire sidewall gave a reasonable prediction of the stress limits and strain distributions, as the shear stresses obtained were within the range of $-10 \mathrm{MPa}$ to $10 \mathrm{MPa}$. The strain energy distributions were found to be within the range of $-1500 \mathrm{~J} \cdot \mathrm{m}^{-3}$ to $1500 \mathrm{~J} \cdot \mathrm{m}^{-3}$. The stress limits for the first principal stress with respect to their magnitudes and orientations was obtained as $10 \mathrm{MPa}$ for tensile stress and -20 MPa for compressive stress respectively while the stress limits for the second principal stress was obtained as $20 \mathrm{MPa}$ for tensile stress and -10 MPa for compressive stress. The plane stress analysis with MATLAB PDE Toolbox gave stress limits distribution in terms of von-Mises stresses in the range $5 \mathrm{MPa}-25$ $M P a$. The results indicate that NR/TSO modi-
\end{abstract}

fied kaolin composites can be employed in automobile tire sidewall applications.

\section{Keywords}

Kaolin, natural rubber, strain, stress, tire von-Mises.

\section{Introduction}

Natural Rubber composites application areas are multifaceted. They can be applied in industrial areas such as automobiles, aerospace, industrial machinery and packaging. In automobiles, Natural Rubber composites are applied to vehicle tire sidewalls and tubes, as door seals and engine seals. In aerospace, they are used in fuel systems. In other engineering fields, they have been applied in conveyor belts, meteorological balloons and bearings of foundations.

Selection of design materials are based on functionality, robustness and improved service delivery. This is of utmost interest to the design engineers. Failure predictions are undertaken for isotropic materials subjected to uniaxial stress. This is to ensure that uniaxial stresses applied on the material do not exceed the ultimate strength of the materials as specified in material 
data sheets, material design handbooks and material selector software. Some serving materials which are subjected to multi-axial stress states require more sophisticated methods to predict failure.

Several authors have published research results on failure prediction using various failure theories. Sadek and Olson [1] worked on new models for prediction of high cycle fatigue failure based on highly loaded regions in multi-axial stress conditions.

Gross and Ravi-Chandar 2] published their results on prediction of ductile failure using a local strain-to-failure criterion. In their study, details of predictive simulations performed in response to the 2012 Sandia Fracture Challenge were reported and the modified JohnsonCook failure criterion partially calibrated with material data obtained from tension test and compact-tension fracture test were employed in a FE simulation to perform a blind prediction of the failure behaviour of the Sandia Fracture Challenge geometry. Mohotti et al. [3] proposed a strain rate dependent constitutive material model to predict the high strain rate behaviour of polyurea. They considered the nine parameters Mooney-Rivlin constitutive material model as the base model in deriving the rate dependent material model which was validated using a high strain material data for polyurea.

Ihueze et al. [4 applied Distortion Energy Theory (DET) implemented with ANSYS software to predict failure of plantain composites subjected to multi-axial stress state.

Crawford [5] reported the various failure theories on maximum stress criterion, maximum strain criterion and Tsai-Hill criterion as appropriate for predicting failure of composite materials.

Previous studies clearly indicate that prediction of the onset of failure is more important than the knowledge of the ultimate strength of the material. The FE Analysis is applied in solving material models that capture the material properties and their external influences. A thorough knowledge of the underlining concepts governing orthogonal stresses, principal stresses and shear stresses of the multi-axial stressed material as shown in von Mises stress theory is required to predict the yield of material.

Theoretical stress-strain relation that fits experimental results for hyperelastic materials have been developed by many authors [6], [7, [8, [9, 10] and [11. Mooney [12] was among the early authors that proposed a phenomenological model with two parameters based on the assumptions of a linear relationship between the stress and strain during simple shear deformation. Treloar (1958) developed the neo-Hookean material model which is based on the statistical theory with only one material parameter which was proved to be a special case of the Mooney model. Earliest developments of the nonlinear hyperelastic theory and its applications relied mostly on Mooney and neo-Hookean strain energy functions [13, [14, [15] and [16].

In this paper, the application of Finite Element Method (FEM) in the prediction of elastic limits for automobile tire sidewall was investigated. This was achieved using elliptical partial differential equation under dirichlet boundary conditions implemented on MATLAB. The analysis is aimed at studying the performance and functionality of Natural Rubber/Tea Seed Oil modified kaolin nanocomposites which were developed for vehicle tire sidewall applications.

\section{Methodology}

\subsection{Materials and Data}

The materials and data used in this work were based on the uniaxial test results obtained from replicated samples of natural rubber/tea seed oil modified kaolin nanocomposites (NR/TSO). The method used in the organomodification process of the kaolin and compounding of the Natural Rubber composites were reported in [17, [18, and [19]. Tensile test result for filler content at $10 \mathrm{phr}$ is shown in Fig. 1. The material properties characterizing the NR/TSO modified kaolin composites were obtained from the stress-strain data as shown in Tab. 1 . 


\section{2. $\quad$ Finite Element Analysis Using MATLAB PDE Toolbox}

The PDE Toolbox in MATLAB can solve Partial Differential Equations that emanates from engineering applications which are domain based and have complex geometries that can be discretized on unstructured meshes. The PDE Toolbox in MATLAB can handle all 2D problems and it also provides an adaptive mesh refinement algorithm for elliptic and nonlinear elliptic PDE problems. The FEA is implemented in MATLAB PDE Toolbox using the elliptical PDE equation under dirichlet boundary condition.

$$
-\nabla \cdot(c \nabla u)+a u=\mathrm{fin} \Omega,
$$

where $\nabla$ is the vector $(\partial / \partial x, \partial / \partial y)$, and $c$ is a $2-$ by- 2 matrix function on $\Omega$. The bounded planar domain of interest $c, a$, and $f$ can be complex valued functions of $x$ and $y$.

For nonlinear elliptic PDE, the nonlinear Newton solver is available for solutions, it is expressed as:

$$
-\nabla \cdot(c(u) \nabla u)+a(u) u=f(u),
$$

where the coefficients defining $c, a$, and $f$ can be functions of $x, y$, and the unknown solution, $u$. All the solvers can address the PDE system with multiple dependent variables:

$$
\begin{aligned}
& -\nabla \cdot\left(c_{11} \nabla u\right)-\nabla \cdot\left(c_{12} \nabla v\right)+a_{11} u+a_{12} v=f_{1}, \\
& -\nabla \cdot\left(c_{21} \nabla u\right)-\nabla \cdot\left(c_{12} \nabla v\right)+a_{21} u+a_{22} v=f_{2} .
\end{aligned}
$$

The major advantage of PDE Toolbox is the simplicity and ease in performing 2D FEA which includes the calculation of stress limits obtained as von Mises stresses, orthogonal stresses etc. with shorter computation time. The PDE Toolbox follows the following simple steps for solving equations:

- Draw the domain using the draw tool in the Graphical User Interface (GUI).

- Set up the appropriate boundary conditions.

- Define the governing equations.
- Generate the mesh.

- Discretize the equations and solve on the mesh.

- Plot the results.

The GUI helps the user get through with these steps.

\subsection{Failure Computations}

The failure analysis for static loading can be summarized for a two-dimensional planar material with the following sets of equations. The stress tensor for a $2 \mathrm{D}$ case is expressed as:

$$
\left[\begin{array}{ll}
\sigma_{x x} & \tau_{x y} \\
\tau_{y x} & \sigma_{y y}
\end{array}\right]
$$

where $\sigma_{x x}, \sigma_{y y}$ are the normal stresses; $\tau_{y x}, \tau_{x y}$ are the shear stresses that act in the direction parallel to $x$ and $y$ axis.

The strain for $2 \mathrm{D}$ case is expressed in matrix form as:

$$
\left[\begin{array}{ll}
\epsilon_{x x} & \epsilon_{x y} \\
\epsilon_{y x} & \epsilon_{y y}
\end{array}\right]
$$

where $\epsilon$ stands for shear strain as represented by their dual subscripts. For a 2D stress state, the principal stress is expressed as:

$$
\begin{gathered}
\sigma_{1}, \sigma_{3}=\frac{\sigma_{x}+\sigma_{y}}{2} \pm \sqrt{\left(\frac{\sigma_{x}-\sigma_{y}}{2}\right)^{2}+\tau_{x y}^{2}}, \\
\sigma_{2}=0 \\
\tau_{\max }=\tau_{13}=\frac{\left|\sigma_{1}-\sigma_{3}\right|}{2} .
\end{gathered}
$$

Von Mises Effective stress as implemented for a $2 \mathrm{D}$ case is either expressed as:

$$
\sigma^{\prime}=\sqrt{\sigma_{1}^{2}-\sigma_{1} \sigma_{3}+\sigma_{3}^{2}}
$$

or

$$
\sigma^{\prime}=\sqrt{\sigma_{x}^{2}+\sigma_{y}^{2}-\sigma_{x} \sigma_{y}+3 \tau_{x y}^{2}}
$$

The strain-displacement relationships which are also determined by the FE solver are expressed as:

$$
\epsilon_{x}=\frac{\partial u}{\partial x}, \quad \epsilon_{y}=\frac{\partial v}{\partial y}
$$


The MATLAB PDE Toolbox can solve 2D FE problems and it also offers an adaptive mesh refinement algorithm for elliptic and nonlinear elliptic PDE problems. In this study, we employ the MATLAB PDE Tool for elliptical equation under dirichlet boundary condition to evaluate structural mechanics plane stresses and the strain distributions. The FEA was executed to predict the stress limits points and strain distributions using elliptical PDE mode on MATLAB.

In this study, the following were assumed for the tire sidewall investigated:

- Only the 2D view of sidewall was considered.

- Static analysis was performed for the NR/TSO modified kaolin composites used as tire material.

- The tire thread and other ply reinforcements were not considered.

- The maximum inflation pressure of $0.220632 \mathrm{MPa}$ for vehicle tire size of P195/55 R16 85H was used in the analysis.

- The applied inflation pressure is assumed to be deformation-dependent so that the pressure always remains normal to the tire internal surface.

- The tire contact surface is assumed frictionless surface in this analysis.

The ISO Metric tire designation for the tire size P195/55 R16 85H investigated is as follows:

P: Passenger tire,

195: Nominal Section Width (measured in millimeters),

55: Aspect Ratio (ratio of the height of the tire's cross section, to its width),

R: Carcass construction ( $\mathrm{R}$ for Radial),

16: Rim Diameter (measured in inches),

82: Load Rating (Service Description, from Load Index table $=515 \mathrm{Kg}$ ),

H: Speed Rating (Service Description, from Speed Symbol table $=210 \mathrm{~km} \cdot \mathrm{h}^{-1}$ ).

\section{4. $\quad$ FEA of Tire Sidewall}

\section{Tire sidewall Geometry}

The NR/TSO modified kaolin composites developed for automobile tire sidewall was found to be hyperelastic with very large deformation upon loading as shown in Fig. 1. The 2D tire sidewall model was developed using draw tool of MATLAB PDE Toolbox as shown in Fig. 2 and it takes into consideration all the details on the tire size following the standard ISO Metric tire designation for the tire size P195/55 R16 85H as shown in Tab. 2. The 2D meshed tire sidewall model has 278 nodes and 448 triangle elements.

\section{Natural Rubber/Tea Seed Oil modified Kaolin Composites}

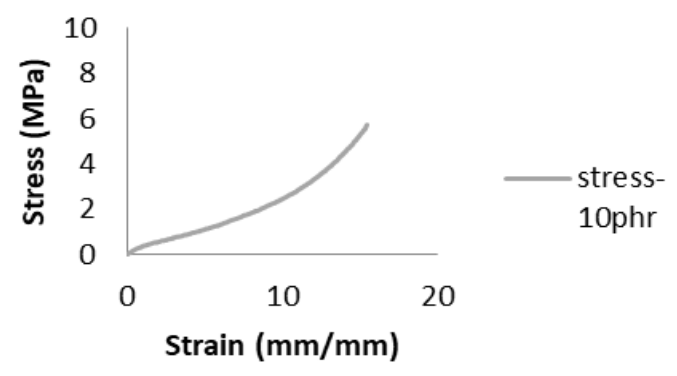

Fig. 1: Natural Rubber/Tea seed oil modified kaolin composites.

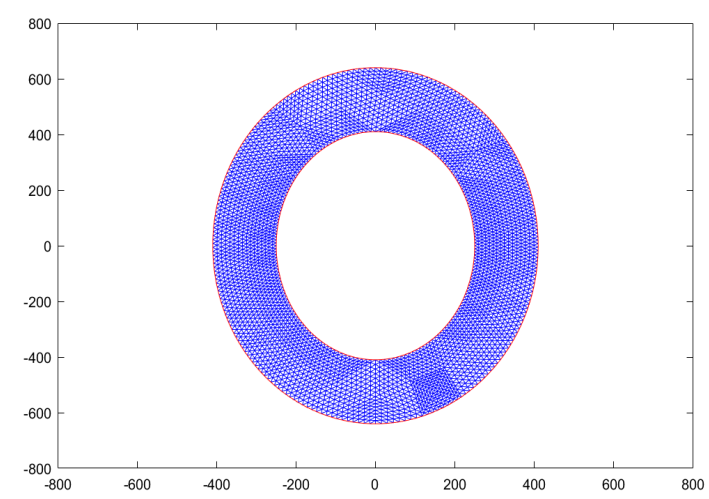

Fig. 2: Tire sidewall mesh showing 3672 nodes and 6912 triangle elements. 
Tab. 1: Material properties of NR/TSO modified kaolin composites.

\begin{tabular}{|c|c|}
\hline Property & Value \\
\hline Elastic modulus, $E$ & $0.0207 \mathrm{MPa}$ \\
\hline Density, $\rho$ & $1974 \mathrm{~kg} \cdot \mathrm{m}^{-3}$ \\
\hline Poissons ratio, $v$ & 0.47 \\
\hline Inflation pressure, $P_{i}$ & $0.220632 \mathrm{MPa}$ \\
\hline
\end{tabular}

Tab. 2: Tire geometry specification for a P195/55 R16 $85 \mathrm{H}$.

\begin{tabular}{|c|c|}
\hline Specification & Dimension (mm) \\
\hline Sectional width & 195 \\
\hline Rim diameter & 410 \\
\hline Outer diameter & 624 \\
\hline
\end{tabular}

\section{1) Boundary Conditions}

A maximum inflation pressure of $0.220632 \mathrm{MPa}$ was applied on the internal surface of the tire in line with the dirichlet boundary condition.

\section{2) Numerical Analyses}

The FEA was performed using MATLAB Partial Differential Equation Toolbox based on structural mechanics, plane stress analysis on the $2 \mathrm{D}$ tire sidewall model.

\section{3) Mesh Convergence Analysis}

To quickly approximate the best results and save considerable computation time, a mesh convergence analysis was conducted. A total of five mesh refinements were considered for the tire model. The von mises stress, shear stress and principal stresses were compared for each mesh refinements, starting from the less dense refinement to the densest refinement using the same material definition for all elements. Table 3 shows the results obtained for the mesh convergence analysis and Fig. 3 is the mesh convergence plot showing the point of convergence of the elements. Mesh model IV with number of nodes 3672 and elements 6912 was chosen for the $\mathrm{FE}$ analysis due to its convergence.
Tab. 3: Results generated from the mesh convergence analysis.

\begin{tabular}{|c|c|c|c|c|}
\hline $\begin{array}{c}\text { Model } \\
\text { Number }\end{array}$ & $\begin{array}{c}\text { Number } \\
\text { of Nodes }\end{array}$ & $\begin{array}{c}\text { Number } \\
\text { of Elements }\end{array}$ & $\begin{array}{c}\text { Von } \\
\text { Mises }\end{array}$ & $\begin{array}{c}\text { Shear } \\
\text { stress }\end{array}$ \\
\hline I & 81 & 108 & 16.5 & 8 \\
\hline II & 270 & 432 & 24 & 10 \\
\hline III & 972 & 1728 & 25 & 15 \\
\hline IV & 3672 & 6912 & 30 & 15 \\
\hline V & 14256 & 27648 & 30 & 15 \\
\hline
\end{tabular}

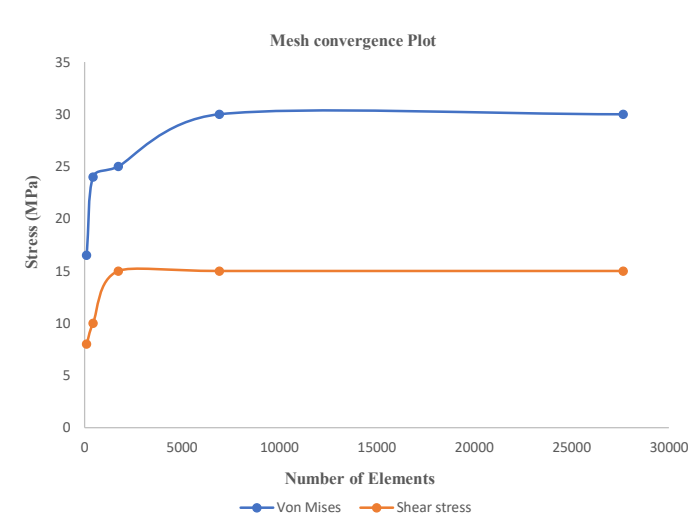

Fig. 3: Mesh Convergence Plot.

\section{Results and Discussions}

\subsection{Shear (Tangential) Stress}

The shear stress of the tire sidewall is developed in a direction parallel to the surface on which it acts. The shear stresses are developed within a body when various layers of material tend to slide with respect to each other 20 . As the tire is inflated to a maximum pressure of $0.220632 \mathrm{MPa}$ internally, the sidewall offers resisting forces which tend to oppose the inflation pressure within the tire sidewall. This resisting force constitutes the shear stresses which are distributed radially over the sidewall geometry. Figure 4 shows the plot of shear stresses of the tire sidewall. A maximum shear stress of $15 \mathrm{MPa}$ obtained for the tire sidewall is situated at the rim area and near the tire thread area. The shear stress offers support and traction to the tire. 


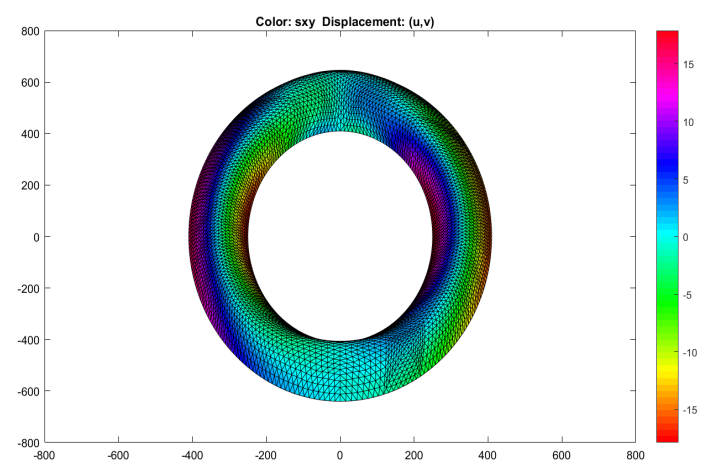

Fig. 4: Plot for Shear stress of the tire sidewall.

\subsection{Principal Stresses}

The first and second principal stresses are an important design criterion used to evaluate structural failures. The magnitudes and orientations of the principal stresses are very important in failure analysis. Figure 5 and Fig. 6 depict the plots of the first and second principal stresses respectively. The stress ranges for the first principal stress with respect to their magnitudes and orientations are obtained as $10 \mathrm{MPa}$ and -25 $\mathrm{MPa}$ respectively while the stress ranges for the second principal stress are obtained as $25 \mathrm{MPa}$ and $-10 \mathrm{MPa}$. The locations of the stresses for this static analysis which was found to be situated around the rim area and the tire thread area contact with the ground within the tire sidewall are very critical for the designer to design against failure and plan for containment to avoid catastrophic failure.

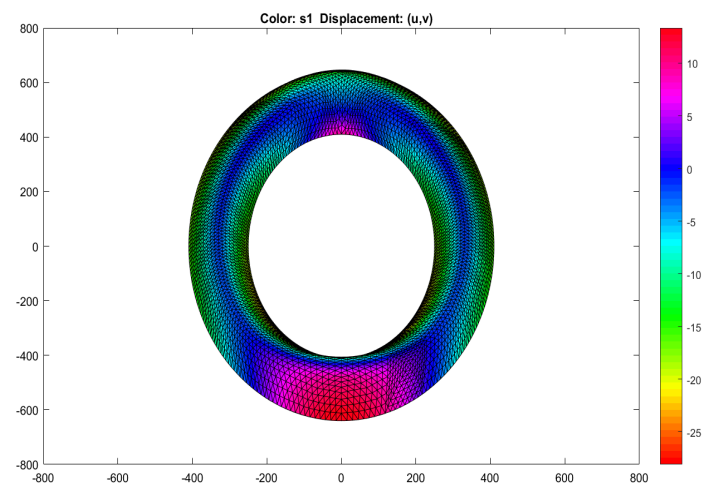

Fig. 5: Plot of the First principal stress.

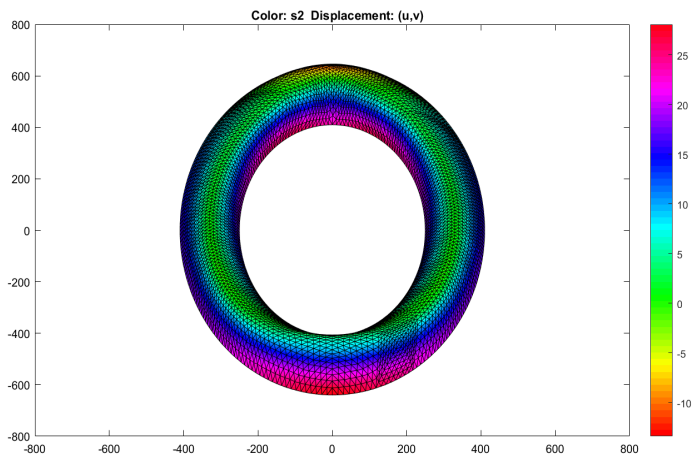

Fig. 6: Plot of the second principal stress.

\subsection{Von Mises (Huber-Henky-Von Mises) Stress}

The von Mises stress is an effective stress that represents the stress situations involving combined tensile and shear stresses. In this study, the von Mises stress was evaluated to be in the range of 5 to $30 \mathrm{MPa}$. With predominant values of $15-20 \mathrm{MPa}$ located on the periphery of the sidewalls.

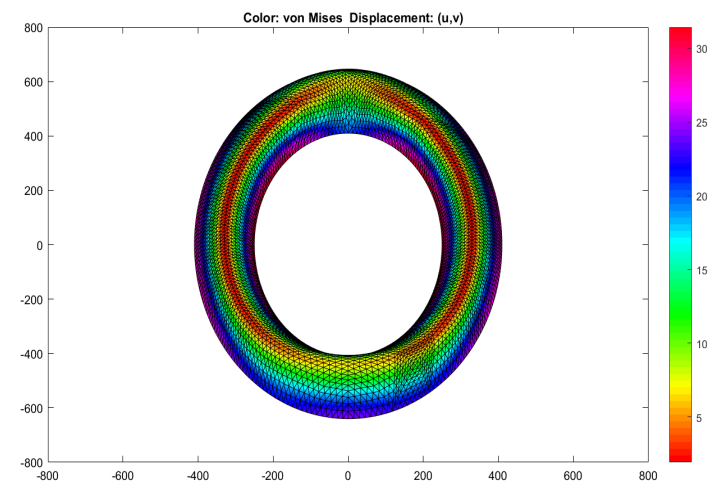

Fig. 7: Plot of von Mises Stress.

\section{Conclusion}

MATLAB PDE Tool was employed in the prediction of stress limits and strain distributions of a $2 \mathrm{D}$ vehicle tire sidewall developed from NR/TSO modified kaolin for P195/55 R16 85 H pneumatic tire subjected to static loading. From the present study, the following conclusions were made: 
- Static analysis performed in this study offered a good analytical evaluation of the tire material studied and is recommended for the use in tire design.

- The MATLAB PDE Toolbox can effectively be used in 2D FEA of structures.

- The Stress-Strain results of NR/TSO modified kaolin composites is hyperelastic at 10 phr.

- Von Mises stresses were evaluated to be in the range $5 \mathrm{MPa}-30 \mathrm{MPa}$.

- The stress limits for the first principal stress with respect to their magnitudes and orientations are obtained as $10 \mathrm{MPa}$ (tensile) and $-25 \mathrm{MPa}$ (compressive) respectively while the limit stresses for the second principal stress are obtained as $25 \mathrm{MPa}$ (tensile) and $-10 \mathrm{MPa}$ (compressive) and as such the material is safely specified with load range of von Mises, $5 \mathrm{MPa}-25 \mathrm{MPa}$.

- The shear stress was evaluated to be in the range $15 \mathrm{MPa}$ for tensile and $-15 \mathrm{MPa}$ for compressive stresses.

\section{References}

[1] SADEK, S. and M. OLSSON. New models for prediction of high cycle fatigue failure based on highly loaded regions. International Journal of Fatigue. 2014, vol. 66, iss. 1, pp. 101-110.

[2] GROSS, A. J. and K. RAVI-CHANDAR. Prediction of ductile failure using a local strain-to-failure criterion. International Journal of Fracture. 2014, vol. 186, iss. 1-2, pp. 66-91.

[3] MOHotTI, D., M. ALI, T. NGO, J. LU and P. MENDIS. Strain rate dependent constitutive model for predicting material behaviour of polyurea under high strain rate tensile loading. Materials and Design. 2014, vol. 53, iss. 1, pp. 830-837.

[4] IHUEZE, C. C., C. E. OKAFOR and C. I. OKOYE. Natural Fibers Composites Design and Characterization for Limit Stress
Prediction in Multiaxial Stress State. Journal of King Saud University - Engineering Sciences. 2015, vol. 27, iss. 2, pp. 193-206.

[5] CRAWFORD, R. J. Plastic Engineering. 3rd ed. Oxford: Elsevier ButterworthHeinamann, 1998.

[6] STEINMANN, P., M. HOSSAIN and G. POSSART. Hyperelastic models for rubberlike materials: consistent tangent operators and suitability for Treloar's data. Archive of Applied Mechanics. 2012, vol. 82, iss. 9, pp. 1-35.

[7] NUNES, L. C. S. Mechanical characterization of hyperelastic polydimethylsiloxane by simple shear test. Materials Science and Engineering. 2011, vol. 528, iss. 3, pp. 17991804.

[8] HAMZA, M. N. and H. M. ALWAN. Hyperelastic constitutive modeling of Rubber and Rubberlike materials under finite strain. International Journal of Solids and Structures. 2010, vol. 41, iss. 18, pp. 5327-5350.

[9] SUSSMAN, T. and K. J. BATHE. A model of incompressible isotropic hyperelastic material behavior using spline interpolations of tension-compression test data. Communications in numerical methods in engineering. 2009, vol. 25, iss. 1, pp. 53-63.

[10] MIEHE, C., S. GOKTEPE and F. LULEI. A micro-macro approach to rubber-like materials-Part I: The non-affine microsphere model of rubber elasticity. Journal of the Mechanics and Physics of Solids. 2004, vol. 52 , iss. 11, pp. 2617-2660.

[11] BOYCE, M. C. and E. M. ARRUDA. Constitutive models of rubber elasticity: A Review. Rubber Chemistry and Technology. 2000 , vol. 73 , no. 3 , pp. 504-523.

[12] MOONEY, M. A. A theory of large elastic deformation. Journal of Applied Physics. 1940, vol. 11, iss. 9, pp. 582-592.

[13] OGDEN, R. W. Large deformation isotropic elasticity - on the correlation of theory and experiment for the incompressible rubber-like solids. Proceedings of the 
Royal Society of London. 1972, vol. 326, iss. 1567 , pp. 565-584.

[14] OGDEN, R. W. Large deformation isotropic elasticity - on the correlation of theory and experiment for the compressible rubberlike solids. Proceedings of the Royal Society of London. 1972, vol. 328, iss. 1575 pp. 567-583.

[15] OGDEN, R. W. Non-linear elastic deformation. 1st ed. New York: Dover Publications, 1984.

[16] OGDEN, R. W. Non-linear Elasticity. 1st ed. Cambridge: Cambridge University Press, 2001.

[17] MGBEMENA, C. O., S. RUGMINI and A. R. R. MENON. Cure Characteristics, Filler Dispersion and Mechanical Properties of Natural Rubber/ Organomodified Kaolin Nanocomposites. International Conference on Rubber \& Rubber-Like Materials. Kharagpur, 2013.

[18] MGBEMENA, C. O., N. O. IBEKWE, A. P. MOHAMED, A. R. R. MENON and S. RUGMINI. Characterization of Kaolin intercalates of Oleochemicals derived from Rubber Seed (Hevea brasiliensis) and Tea Seed (Camelia sinensis) Oils. Journal of King Saud University-Science. 2013, vol. 25 , iss. 2, pp. 149-155.

[19] RUGMinI, S. and A. R. R. MENON. Organomodified Kaolin as Filler for Natural Rubber. Journal of Applied Polymer Science. 2008, vol. 107, iss. 6, pp. 3476-3483.

[20] SPIEGEL, L. and G. F. LIMBRUNNER. Applied Statics and Strength of materials. 3rd ed. New Jersey: Prentice Hall, 1998.

\section{About Authors}

Chinedum Ogonna MGBEMENA is a senior lecturer in Mechanical Engineering Department of the Federal University of
Petroleum Resources, Effurun, Nigeria. He completed his undergraduate and postgraduate studies at Nnamdi Azikiwe University, Nigeria. His research areas are: Polymer Composites, Modelling and Simulation of manufacturing processes, Computational Mechanics and Failure Analysis. He has held various research and lecturing positions in Nigeria, India and United Kingdom.

ThankGod Enatimi BOYE received his BEng. (Hons) and M.Sc. in Mechanical Engineering from the University of Sunderland and Birmingham City University, United Kingdom in 2010 and 2012 respectively. He is a registered Engineer with (COREN), a corporate member of the Nigerian Society of Engineers (NSE) and member of the Nigerian Institution of Mechanical Engineer (NImechE). He is currently a lecturer in the Mechanical Engineering Department, Federal University of Petroleum Resources, Effurun - Warri Nigeria. His PhD research is in-view and he has been from inception the supervisor of the record breaking Team FUPRE Shell Eco-marathon project in South Africa 2015 to 2017. He also has many local and international awards in is comfy. His area of research interest includes, computational fluid dynamics, numerical simulation, automobile design, fabrication and testing, pipeline design and transient flow simulation, finite element analysis, applied energy and oil and gas industrial equipment maintenance.

Ikuobase EMOVON is a senior lecturer in Mechanical Engineering Department of the Federal University of Petroleum Resources, Effurun, Nigeria. He obtained his PhD degree in Maritime Technology from Newcastle University, Newcastle Upon Tyne, United Kingdom. His research interest are; engineering system maintenance modelling and optimisation, risk analysis and multi-criteria decision making in industrial system environment. The author has published several papers in reputable international Journals such Applied Energy, Applied Ocean Research and Ocean Engineering and he is a reviewer to some of these Journals.

"This is an Open Access article distributed under the terms of the Creative Commons Attribution License, which permits unrestricted use, distribution, and reproduction in any medium, provided the original work is properly cited (CC BY 4.0)." 